\title{
The Successful Educational Journeys of American Indian Women: Forming Aspirations for Higher Education
}

\author{
Maureen Snow Andrade \\ Utah Valley University
}

American Indians (Als) have lower higher education enrollment and completion rates than Whites and most minority groups. Al women, however, participate at higher rates than Al men, White women, and White men. Research has not examined what contributes to their higher education aspirations. This study explored the middle and high school experiences of educationally successful Al women to determine how academic factors-activities within and beyond school and relations with peers, teachers, and counselors-affected their enrollment decisions. Findings indicate that academic engagement, community and culture, resiliency to challenges, and knowledge of higher education contribute to aspirations. Implications are discussed.

\author{
Literature Review \\ Methods \\ Results \\ Discussion \\ Implications and Conclusion
}

Higher education attainment results in economic growth, global competitiveness, decreased crime and poverty, and increased civic engagement (American Human Development Project, 2009; Aud et al., 2011; Carnevale, Smith, \& Strohl, 2010; College Board, 2007; Lumina Foundation for Education, 2010). Ensuring that individuals of all ethnicities form aspirations for and complete higher education is of critical importance. This is particularly true for those who struggle with poverty, societal problems, and historical inequities. In the case of American Indians (Als), education may represent a pathway to "sovereignty, self-determination and tribal development" (Fann, 2004, p. 14).

Relatively few Als enroll in and complete higher education. This is due to a variety of factors such as non-completion of high school, insufficient educational preparation, limited admission and financial aid information, lack of desire, weak institutional or family support, and culture (e.g., see Guillory \& Wolverton, 2008; Kanu, 2006; Lee, 2007; Tierney, Sallee, \& Venegas, 2007). Only $78 \%$ of Als over the age of 25 complete high school compared to $92 \%$ Whites, $89 \%$ Asian/Pacific Islanders, 83\% Blacks, and 62\% Hispanics (National Center for Educational Statistics [NCES], 2010).

Approximately $39 \%$ of Als complete a bachelor's degree in six years (NCES, 2012). The comparable figure for Whites is $56 \%$ for males and $61 \%$ for 
females (NCES, 2012). Women comprise $57 \%$ of the total higher education enrollment (NCES, 2012). Al women exceed this slightly, representing 59.9\% of Al higher education enrollments (NCES, 2010). In spite of this, however, no research has focused on how Al women form aspirations for higher education.

This exploratory study examined factors affecting Al women's aspirations for higher education, specifically those associated with schooling and nonschooling experiences during the middle and high school years. These included academic factors; activities and involvements in school and beyond; and relations with peers, teachers, and counselors. The study aimed to determine which aspects of the women's experiences helped them form aspirations and led to completion of either an associate's or a bachelor's degree.

\section{Literature Review}

Success factors for Als in higher education include structured pathways in high school such as academic preparation, financial support, and admissions information, as well as sociocultural factors, including role models, supportive family members, teachers and peers, and educational systems that reinforce indigenous ways of knowing (e.g., see Brayboy, 2004; Castagno, 2005; Guillory \& Wolverton, 2008; HeavyRunner \& DeCelles, 2002; Jaime, 2003; Lee, 2007; Saggio \& Rendón, 2004; Shotton, Oosahwe, \& Cintrón, 2007; Waterman, 2007). Few studies have examined middle and high school experiences and factors affecting higher education aspirations. None has focused on how these factors affect the enrollment decisions of Al women. As this is an exploratory study with no existing literature base, this section reviews relevant research and theories to provide an overview of possible factors related to the formation of aspirations for Al women.

\section{Structured Pathways}

One reason Als fail to enroll in or complete higher education is poorly structured pathways related to academic and financial preparation. Large numbers of Al students drop out of high school, and few take needed admissions exams (Tierney et al., 2007). Students recognize their lack of preparation and suffer from the low self-esteem that accompanies it (Doyle, Kleinfeld, \& Reyes, 2009; Guillory \& Wolverton, 2008; Jaime, 2003; Kanu, 2006; Woodcock \& Alawiye, 2001). However, when Al perspectives are integrated into high school courses and extracurricular activities, not only does student performance and attendance improve, but also the understanding of Al culture and history along with pride and self-confidence (Kanu, 2006).

Even when Als have higher education aspirations, they may fail to realize their goals due to poor academic preparation, the need for more structured 
pathways (e.g., scholarships), direct personalized assistance, ambivalence about leaving their villages, and no knowledge of how to realize their goals (Doyle et al., 2009). Their parents may lack information about college and be unable to help, and their schools and counselors often do not focus on college preparation or provide needed information (Fann, 2004). Thus, young Als are responsible for finding information about college on their own.

Additionally, students must navigate a complex system of federal and tribal aid, which is often in the form of loans rather than grants, and may be reluctant to incur debt (Tierney et al., 2007). Although multiple sources of aid are available, those who need it may not know how to access it (Tierney \& Venegas, 2006; Zarate \& Pachon, 2006), lack unfamiliarity with how to apply (Corwin, Venegas, Oliverez, \& Colyar, 2004; Fann, 2004; Tierney, Colyar, \& Corwin, 2005), or view higher education as unaffordable (Tierney et al., 2005).

\section{Sociocultural Influences}

Sociocultural factors, specifically the influence of schooling, peers, and family, affect aspirations by influencing values and goals for educational attainment. The Model of Future Oriented Motivation and Self-Regulation posits that sociocultural factors influence goals and that the achievement of goals positively affects motivation (Brickman \& Miller, 2001; Miller \& Brickman, 2004). Additionally, when students are future-oriented-viewing schooling as a means to attaining future goals-motivation, effort, self-regulation, academic success, and aspirations are positively affected. In the case of $8^{\text {th }}-12^{\text {th }}$ grade Al students, belief in the instrumentality of education predicted their intentions to attend university; teachers and peers facilitated students' positive attitudes toward schooling (Brickman, Mclnerney, \& Martin, 2009).

Similarly, validation theory, or the influence of teachers, peers, faculty, and staff in affirming students as capable of educational success, fosters students' academic development and belief in their abilities. Al students at a Bible college reported benefitting from family members who helped them apply, encouraged them to excel, and served as role models (Rendón \& Saggio, 2004). They also attributed their success to the sense of community at the college, including being welcomed by the faculty, having opportunities for spiritual enrichment and building religious faith, and having a church family. Similar pre-college validation from family, teachers, and peers would likely be helpful in forming aspirations.

Validation theory has been particularly valuable in providing a perspective on the experiences of students from a variety of ethnicities who may have experienced "invalidation in their prior learning experiences," including a lack of role models and a lack of belief in their own abilities (Linares-Rendón \& Muñoz, 2011). Academic environments based on a funds of knowledge paradigm, which entails recognizing and building on what students bring with them to the classroom in terms of their own and their families' cultural ways of knowing and 
skills sets rather than on a deficit model (Moll, Amanti, Neff, \& Gonzalez, 2001), are related to the concept of validation and have proven valuable in promoting successful practices that support the success of ethnically diverse students.

A disconnect between school and home cultures can affect academic aspirations and achievement. The concept of Indigenous Knowledge Systems posits that integrating traditional cultural values and Western ways of thinking (Barnhardt \& Kawagley, 2008) can aid learner success by acknowledging and respecting indigenous ways of knowing (Brayboy, 2004, 2005a, 2005b). According to TribalCrit theory, educational contexts that support the maintenance of cultural identities are central to academic achievement (Brayboy, 2005a). These theories are related to the funds of knowledge approach in that they support and respect cultural knowledge and learning processes. Schooling in the middle and high school years that has a foundation in these tenets is more likely to support the development of aspirations for Al students as well as the motivation and confidence that leads to enrollment and success.

While research indicates that academic and social integration has a positive impact on retention and persistence in higher education (Astin, 1984, 1993; Tinto, 1987, 1993), it is unclear how these involvements may impact aspirations, and specifically for Al women. However, involvements that support cultural efficacy in higher education contexts validate Al students and support their success (Barnhardt \& Kawagley, 2008; Brayboy, 2004, 2005a, 2005b; HeavyRunner \& DeCelles, 2002; Waterman, 2007). Indeed, "validation may be the missing link to involvement, and may be a prerequisite for involvement to occur" (Rendón, 1994, p. 37). However, connections within and outside the educational context may take different forms for Al students than for traditional students.

In sum, aspirations may be positively influenced by structured pathways consisting of practical information, guidance with application processes, and financial support. The Model of Future Oriented Motivation and Self-Regulation and validation theory demonstrate that socialization regarding the value of education and the affirmation of academic ability also impact aspirations and achievement. Academic preparation that validates culture and develops cultural identity, as indicated in Indigenous Knowledge Systems and TribalCrit theories, increases self-efficacy and possibly aspirations. Using this research as a foundation, the present study explored how middle and high school experiences, academic factors, relationships, and academic and non-academic involvements influenced the aspirations of Al women.

\section{Methods}

This exploratory study focused on Al women graduates from a single institution to identify factors relevant to their success. The study addressed the research question: How do schooling and non-schooling experiences during the 
middle and high school years influence the higher education aspirations of educationally successful Al women? The focus was on women who had completed some level of post-secondary education. The researcher's scholarship and teaching has concentrated on understanding and helping culturally and linguistically diverse students make an effective transition to and succeed in higher education; thus the interest in aspirations and completion for Al women. The results of the study potentially impact the researcher's influence on institutional processes as an administrator and classroom practices as a teacher.

The names of Al women who had graduated with either an associate's or bachelor's degree in the past five years from a large, regional, public university were obtained for recruitment purposes. A total of 50 women were contacted and eighteen (36\%) agreed to participate. The sampling was purposive in that it focused on a particular subset of Al women (those who had been successful) in order to understand their experiences. Because limited research exists on Al women's educational aspirations, this approach was appropriate. The number of participants allowed for saturation in that the information provided in-depth understanding of participants' aspirations. As with all qualitative studies, causality cannot be claimed. Instead commonalities and differences can be identified and presented as factors relevant to aspirations for higher education for the participants. In keeping with qualitative research practice, this study does not attempt to prove or disprove a particular theory although several theories guide the study.

Fifteen participants had resided for over 12 years in the state where the study was conducted. Twelve had completed high school in the state and six outside of the state. Of these, six had attended Al high schools with an additional two attending high schools with Al enrollments of approximately $70 \%$. Ten had associate's degrees and eight had achieved bachelor's degrees. None was currently enrolled. Their average age was 30, with a range from 21-40. Seven were single, six were married, and five were separated or divorced.

Data were collected through an interactive online tool that allowed the researcher to monitor responses, encourage development of the responses, and set time limits. Participants were asked to spend 3-5 minutes per question. They were instructed to keep writing until the time was up, provide as much detail as possible, and answer honestly. By moderating the data collection, some of the disadvantages of administering the questions from a distance were addressed. The procedure simulated an interview although it was online with written responses. The procedures accommodated participants located throughout the state where the research occurred. It also encouraged the women to share information about their lives independent of direct, face-to-face interviewer influence (Attinasi, 1992; Kvale, 1996). Disadvantages of this method include lacking the opportunity to establish rapport or put the interviewees at ease and the possibility that their written skills might not be as strong as their oral skills or as effective in communicating their ideas. Also, the use of the technology could be intimidating or affect participant confidence levels in some way. 
The instrument had a demographic section followed by open-ended questions that outlined central issues related to participants' schooling and nonschooling. As this was an exploratory study, the use of broad questions with guiding prompts was designed to identify the issues and elicit in-depth feedback. Respondents were provided with information about the study and signed informed consent forms, following IRB protocols. The instrument consisted of the following questions and probe:

1. Describe your middle and high school experience(s). For example, did you enjoy it? Did you learn a lot? What were the best parts of school? What were the worst parts of school? Describe the academic and social culture of the schools you attended.

2. Describe the types of courses you took in high school (e.g., electives, music, advanced placement, concurrent enrollment, career and technical education, skill/work-based learning, etc.).

3. Describe involvements such as leadership roles and other activities during your middle and high school years (e.g., clubs, athletics, volunteer work, youth groups, student government, employment, household/childcare duties, socializing, etc.)

4. Did anyone at high school talk to you about college? If so, who? Describe the influence of teachers, high school counselors, and administrators on your college decisions. Describe any career and college counseling you received during middle school or high school (this includes any support or assistance with college applications, application essays, financial aid applications, and so forth). Did anyone talk to you specifically about financial aid? If so, who?

5. Did your friends and peers in high school talk about college? What did that tell you about college? Did your friends go to college?

Data analysis involved grouping the responses under the survey questions and reading and rereading them to identify consistencies and differences. This process was framed by the research questions. It was also guided by the literature, specifically the factors shown to influence aspirations. The constant comparative method, which focuses on identifying response patterns and themes (e.g., see Glesne, 1999; Lincoln \& Guba, 1985; Tesch, 1990) was utilized. Codes were formed to identify key ideas and create categories.

\section{Results}

In this section, the themes are considered in relation to the research question and guided by the literature review to determine how schooling and non-schooling experiences during participants' middle and high school years helped them form aspirations for higher education. The findings were consistent among both associate and bachelor degree completers. 


\section{Academic Engagement}

The women's middle and high school experiences were overwhelmingly positive. Almost without exception, they stated that they enjoyed school. For instance, "I enjoyed math." "I thoroughly enjoyed middle and high-school. It was an experience I will never forget and would never change." "I enjoyed school. It gave me the chance to get away from herding sheep." "I loved going to school. I loved learning things every day. I liked to learn things and then ask questions and to try it out." "I believe some of the more challenging classes prepared me for college." They liked homework and excelled at it.

The participants took courses that provided strong academic preparation. These included concurrent enrollment, advanced placement, and honors. Some completed high school with college credit or technical certifications. Most mentioned taking core subjects such as math, English, and science as well as art, music, drama, foreign languages, and history. Several had enrolled in career and technical courses, including business, pharmacy, medical assistance, welding, shop, and computer technology. Other courses such as swimming, volleyball, photography, sewing, and fashion design were mentioned. The range and types of courses provided participants with opportunities to explore and develop their talents, skills, and interests and to recognize the benefits of a wellrounded and solid academic experience.

Nearly all participants reported getting good grades and being motivated. One woman stated: "I learned a lot about having academic goals and aspiring to new heights.... My freshman year, by the end of the school year, I had straight A's. I was so proud of myself!!!!!!" Excelling in academics helped them believe they could do well if they continued their schooling and also assisted in career exploration as indicated in the following statement: "I believe I did learn quite a bit, the courses I took in high-school helped me decide what to major in."

Another aspect of participants' academic engagement was involvement in co- and extra-curricular activities such as academic clubs, sports, yearbook committees, music, dancing, and cultural events (e.g., pow wows). One woman described her high school years as follows:

I enjoyed school thoroughly, but mainly at a social level. I had lots of friends, attended all school activities, and belonged to several groups and clubs. I wasn't as interested in the learning aspect of school until college, however, I still somehow managed to get good grades and graduate with honors.

Participants obtained some leadership experiences such as volleyball team captain, honor society secretary, class president, student newspaper editor, student body vice president, and swimming team captain. These involvements extended the women's learning and growth opportunities beyond the classroom. 
They valued learning and had opportunities to explore their interests-factors conducive to forming higher education aspirations.

\section{Community and Culture}

In most cases, the middle and high school years were characterized by feelings of community with friends and teachers. One woman stated: "The social culture of the high-school was one where everyone got along with one another." Another shared how having like-minded friends was a positive factor in her continued enrollment: "Middle school was a lot of fun because I hung out with friends that cared about grades and they wanted to go on to high school. Another said, "I felt really safe and had good friends that enjoyed school also."

Peer pressure was a problem in some instances. One woman indicated that her "strict upbringing" did not allow her to fit in. "No parties or boyfriends allowed and so it put some strain on my peer relationships, but for the most part I stayed away from bad influence.... I had the most fun with my academic type clubs." Another stated she enjoyed school but "started doing things [she] shouldn't have been doing." Her grades fell and she dropped out in her senior year. She indicated the following:

Peer pressure played a major role. I felt I didn't have the stability I needed and so I looked for acceptance in other places and ways. My parents were going through a lot of rough patches and were not around most of the time.

Participants received encouragement from friends to attend college and talked to friends about college. These discussions focused on where they intended to go and possible majors. They indicated that most of their friends had gone to college. Only one participant, an associate's degree completer, had experienced negative reactions from friends toward college:

People didn't talk about college in high school. The consensus there is that leaving the reservation is bad for the people. I wouldn't say college is banned, just probably not a priority, which is a shame. It was something I never really understood, and something I still am confused about.

Another indicated that her White friends talked about college and received degrees, but her Al friends did not discuss it. Other than these two instances, regardless of whether or not the participants attended predominantly Al high schools, they were supported by friends in their educational aspirations.

Another aspect of this theme was comfort with cultural differences. With the exception of a few, the participants reported positive experiences regardless of whether or not their schools were ethnically diverse. One woman described herself as a minority, but stated, "I never felt that I was an outcast at all or at any time." Another, who had completed an associate's degree, described her experience in two very different school settings. 
I was the only Native American in that school with a majority of white students.... I had no problems socially. I actually had a lot of friends and being native among them was no problem. Sometimes I felt like one of them. I loved them all. My last two years of high school was... a big total culture shock for me. I felt like I stood out like a sore thumb. The cultures of students were made up of whites, Hispanics, blacks and different native tribes. I thought I would never get used to them.

In contrast, a participant indicated appreciation for diversity in her school.

The school consisted of mainly white students but there were several students that came from outside the country because we were on a military base.... I had friends from Japan, Guam, India, Italy, Africa, Samoa, France, England, and Spain. I loved being with all of these people from different countries because at that age, it showed me that not every person in the world is going to look at me with a certain image in mind like most Americans do. Those friends that I made at that age helped me so much in getting over the cultural barriers that surround many of us today.

The majority of participants did not feel that relationships with those from other cultures had an influence on their aspirations. They felt connected to peers and embraced their own culture, however, which likely had an impact on their positive views of school. One said: "The people that I interacted with in high school had the same ideas and values as I did."

Feelings of community extended to teachers with a few exceptions. Commonly mentioned were teachers who "saw promise" in their students and helped them "believe that [they] could do whatever [they] wanted" in life. One woman stated that her math teacher was "a man who accepted everyone and had high expectations." The majority reported that they had received encouragement from teachers.

In a few cases, participants had experienced prejudicial treatment. One participant and her friends had been told by a chemistry teacher that "none of [them would] make it through the first year of college." Their retort was, "Just watch." This particular woman completed a bachelor's degree. Another bachelor's degree completer had difficulties with a teacher who segregated the class. She said, "The white students would be on one side of the room and all of the colored students on the other. In [the teacher's] mind, he was separating the good students that listened from the bad students that always argued back." The participant noted that the teacher did not recognize his actions as racial segregation.

Another woman, schooled on a reservation, "enjoyed school," but indicated that "the worst parts of school were some of [her] teachers." Her VISTA and Peace Corps teachers thought "it was their duty to introduce... [students] to drugs and other crazy notions." Students were invited to parties at the teachers' homes and even used drugs with teachers at school. This participant said, "We had to make choices and I ran with a group of people who chose differently.... 
[The teachers] would stay only long enough to fulfill their duty and be gone leaving a trail of addiction behind them."

Community with friends and teachers in school settings was a commonality among most participants. Their experiences indicated the powerful positive and negative impact of peers although negative experiences, especially with teachers, often resulted in strengthened educational commitments. Participants were generally comfortable with diversity and their cultural identities and interacted well in a variety of cultural contexts.

\section{Resiliency to Challenges}

The data demonstrated predominantly positive schooling and nonschooling experiences although challenges were evident. Resiliency, or the ability to see beyond the present, manage difficulties, and persist in their educational goals, coupled with strong educational values, was a strengthening factor in these cases.

As mentioned earlier, peer pressure was an issue. Three participants indicated that they felt they could not "fit in the social scene" in high school. One stated that "the peer pressure focus made going to school more stressful than it needed to be." Another observed that she "enjoyed most of [her] classes during high school and junior high," but that the social aspect "was probably the toughest part." In one case, a participant experienced both social and academic challenges:

The worst parts about school were I felt I wasn't very smart and I didn't have very many friends. I also felt I didn't fit in with the culture because I was brown and everyone was white and smarter and had more friends. I was always behind in my English class.... I didn't like high school that much...until I started to get A's and B's and my last year in high school I got a 4.0. I feel I didn't learn a lot but that I was a slow learner and didn't get the hang of things 'til I was out of high school. The best part about school was I was very good at sports and loved to play soccer.

This participant achieved an associate's degree in spite of social discomfort and a lack of confidence about her academic abilities. She had strong encouragement from family - getting a degree was an expectation-and she was motivated by the desire to complete her education in order to "help others."

The women experienced different pathways to academic success. In most cases, they were able to balance social and academic demands as evidenced by one participant who completed a bachelor's degree but indicated not being "interested in the learning aspect of school until college." She was involved with social activities, yet "managed to get good grades and graduate with honors." Additionally, academic achievement was sometimes affected by family situations. 
My middle school experience was okay.... It set the ground for my interest in Music. I played the flute and clarinet.... My freshman year I was quite successful and numerous teachers recommended I take the state core exams and work on graduating the following year. I did not attend school for my sophomore and junior year. I stayed home to help my parents raise my siblings, and then my senior year I attended another high school. I had taken the state core exams and passed all required courses to graduate that year with my class and ranked as 2 nd in my graduating class.

Although this woman's education was interrupted in order to support family, positive experiences in the form of teacher encouragement and academic success motivated her to complete high school and an associate's degree.

Home life was sometimes unsupportive of academic success as mentioned earlier, as was peer pressure and bad choices. Another issue evident was coming to terms with culture and history.

Junior high was somewhat of a challenge. I was...quite bitter over my people's situation. I felt like we were cheated of life. As though the government and the white race had set us up to fail no matter what we did.... My family knew what I was going through and they did what they could to calm my anger because they experienced the same feeling at one time or another.... I spent a lot of time with the old people and I slowly began to see that being angry and hateful were not likely to help my people or change our troubles.

Peer pressure, bad choices, family problems, and racial identity were key challenges. However, the participants demonstrated resiliency to accomplish their educational goals. In each case, something or someone helped the women dig deeper to overcome challenges. These influences varied but included encouragement from teachers; insights from family, elders, and friends of their own or other cultures; or personal commitment.

\section{Knowledge of Higher Education}

The final theme that impacted aspirations was knowledge of higher education. In some cases, participants had only vague notions of college and what it entailed. One woman explained: "My friends always spoke about what they wanted to achieve in college but none of them had been there before so they knew very little. We could only feed off of what our parents, siblings, or teachers had told us." In other words, they relied on the experiences of others. In another case, a participant had been accepted with a scholarship while her friends "were not sure where to attend or where to apply." This "told [her] that [she] had more things in life figured out than they did." Access to admissions and financial aid information helped her realize her aspirations. 
A few observed that formal programming helped prepare them for college. "Upward Bound taught me about the application process of everything, FAFSA, scholarships, applications, very important stuff." Another remarked that career day in middle school had been helpful, and one valued the involvement of her counselors in encouraging her enrollment in summer school college preparation programs. These participants had access to needed information in order to plan and prepare for college.

Information about higher education provided by high school counselors varied. In some cases, visits to counselors and information obtained was perfunctory-including flyers being passed out, obligatory visits, or those who were perceived to just be doing their jobs. "I felt [my counselor] wasn't sincere [but was] just doing it [providing information about college] because it was her job." In other cases, counselors may not have pursued discussions if they perceived students were not interested.

I didn't receive much career and college counseling in middle or high school.... So, I did a lot of things on my own. Financial aid was only brought up once by a counselor...but I told her that it was a route that I wasn't interested in.

Another said: "We had an AWFUL school counselor that told us NOTHING of concurrent enrollment. Had I known, I feel I could have graduated from college earlier. I was enrolled in all honors courses." This woman completed a bachelor's degree but could have earned tuition-free college credit.

Other participants had had enormously positive experiences with counselors. One had mandatory career counselor appointments in which she discussed where to go and what her area of study would be. In another case, the counselor "never asked [the students] if [they] were going to go [to college] but rather what college [they] were planning on going to." This participant indicated that her counselor "was awesome. Helped each one of us with college applications, scholarships and so forth. I owe much to him." Another counselor talked to students about careers and how to pursue them and made sure that their high school courses were preparing them for future degrees. One participant tells how her high school counselor opened the door to her aspirations:

While I was in high school, I did not think much about attending college. I was not educated about college, and I did not know how much college costs or where I would go. I honestly thought college was not for me. My senior year, my high school counselor recommended the Pharmacy Technician Program to me.... I began taking this course during my free periods in high school. I ended up loving the program. This is when I began to think about going to college and getting a degree. As soon as I graduated, I registered for classes at my local college.

Access to information and knowledge about higher education application, admissions, enrollment, and financial aid processes had an impact on aspirations. High school counselors were central to providing information about 
these processes although some were not as effective as others. In a few cases, parents, teachers, and formal programming filled this role.

\section{Discussion}

The four themes identified in this exploratory study-academic engagement, community and culture, resiliency to challenges, and knowledge of higher education-provide insights into how schooling and non-schooling experiences were linked to higher education aspirations for Al women who successfully completed some level of higher education. The findings generally support the literature although this study presents new insights.

The findings are consistent with research related to the Model of Future Oriented Motivation and Self-Regulation and to validation theory (Brickman \& Miller, 2001; Miller \& Brickman, 2004; Rendón, 1994; Rendón \& Saggio, 2004). Sociocultural influences that demonstrate the benefits of education, coupled with engagement in academics and positive feedback, contributed to the women's aspirations. Their academic preparation, social and cultural experiences, and involvements supported the development of educational values and goals. Positive academic experiences affirmed their ability to achieve. Validation and encouragement from social contexts (i.e., family, peers, teachers) created feelings of community and opportunities to discuss educational goals.

Cultural identity and pride encouraged the women to interact with and be positively influenced by diverse peers. Such an attribute potentially addresses the conflicted feelings faced by Al youth about leaving homes and tribes for higher education (Fann, 2004). Although the study did not reveal how coursework may have integrated Indigenous and Western ways of knowing (Barnhardt \& Kawagley, 2008; Brayboy, 2004, 2005a, 2005b; Kanu, 2006), the women were comfortable with their cultural identities and most had thrived in interracial educational settings, suggesting that their social and academic environments were culturally inclusive and responsive to their cultural funds of knowledge to some degree (Moll et al., 2011). While there was some mention of a lack of support for higher education within the Al community, the participants felt prepared for college, including those who had attended Al high schools.

Negative schooling, family, and social experiences did not deter the women from their educational commitment. In cases in which participants were lacking in an area such as academic engagement or validation, another area compensated. For instance, if a woman lacked confidence and felt social discomfort at school, encouragement and support from home countered this. Although a few had negative family or school-related experiences, the presence of a sufficient number of positive factors contributed to resiliency.

Finally, knowledge of higher education in terms of access to information was a factor. The women had sources of information including peers, family, teachers, and counselors. In several cases, teachers and counselors were 
instrumental in extending help, encouragement, and identifying pathways. Research demonstrates that a lack of this information inhibits enrollment and success (Doyle et al., 2009; Fann, 2004; Guillory \& Wolverton, 2008; Jaime, 2003; Kanu, 2006; Tierney et al., 2007).

The findings represent the individual experiences of self-selected participants who had successfully completed degrees at a single institution. As such, the results cannot be generalized, nor do they provide insights into why Al women may choose not to participate in higher education. The findings do identify possible factors related to the educational aspirations of Al women that could be further explored.

The study relied on the women's memories regarding their schooling experiences. Retrospective studies are based on participants' perceptions and interpretations of the past. While powerful to them, these depictions may not be entirely accurate. The detail in participants' depiction of events, however, demonstrates clear, distinct, and compelling memories. As individuals view events from their own perspectives, information about any life experience is colored by individual ways of thinking and seeing and is a factor in all such research.

\section{Implications and Conclusion}

Although some factors affecting aspirations may not be easily addressed, others are achievable. More can be done in middle and high school to prepare students who may not be considered "college material." The presence of validation, goals, and clear pathways for application and admission processes makes a difference. Opportunities for concurrent enrollment, advanced placement, and honors courses must be available, and appropriate college preparatory course work should be required. Teachers and counselors must serve as role models and information sources. They should talk with students about the benefits of college and strategies for college preparation. Administrators can provide in-service training related to diverse students; the need for encouragement, support, and information; and ways to help these students plan, prepare, and set goals.

Information must be provided to students and their families. Data related to the benefits of higher education, job opportunities, and options must be disseminated. Outreach from local higher education institutions, precollege programming, counseling, and workshops designed for potential students and families, particularly when offered by Al role models, can address this need. The latter might include supplemental coursework, parent seminars, and application and financial aid information beginning in junior high to create vision and establish pathways to higher education.

Helping Al women develop aspirations for higher education is a shared responsibility. It occurs through formal educational structures and programming 
within schools as well as informal interactions of individuals in students' lives. Figure 1 illustrates the factors associated with creating a culture of higher education aspirations based on the findings of this study. Ideally, these factors would be integrated to establish a multi-faceted approach. Their presence can assist Al women in forming the attitudes and attributes necessary not only to aspire to higher education but to successfully complete it.

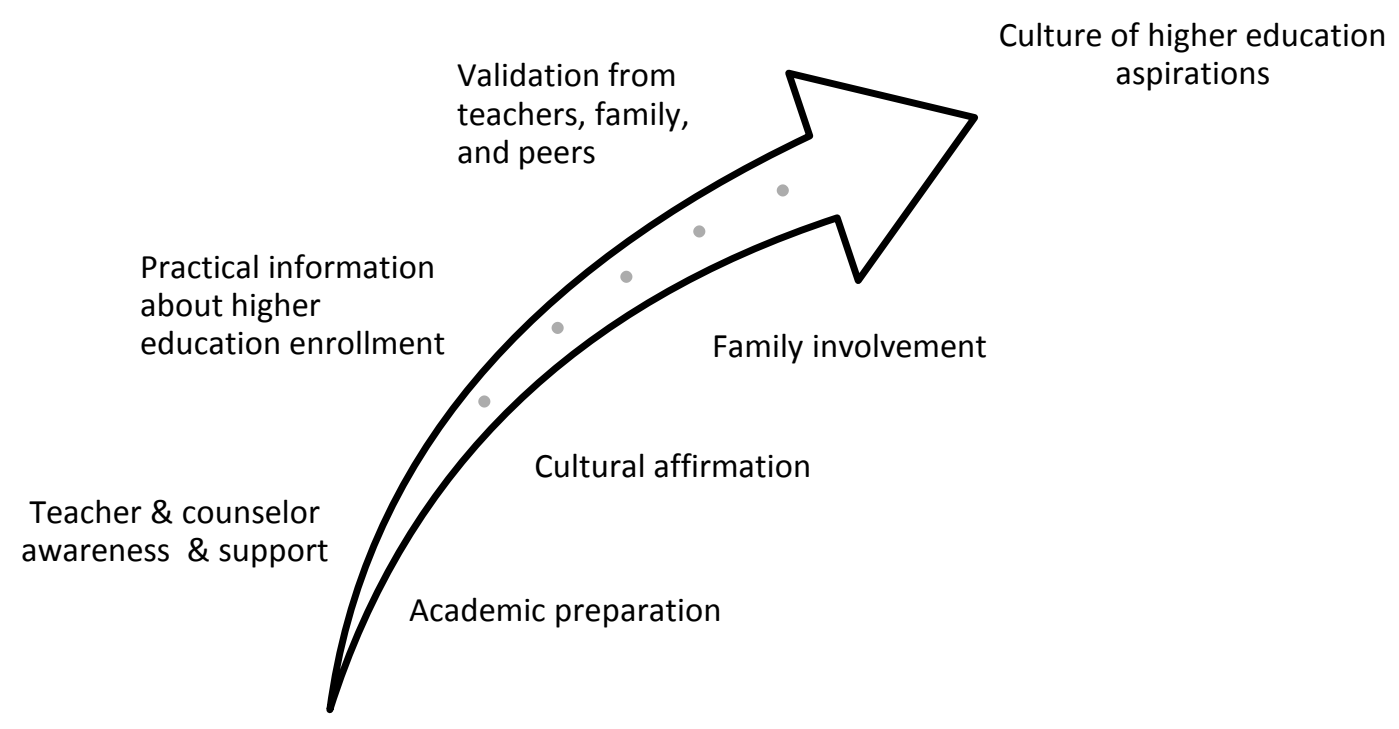

Figure 1. Creating a culture of higher education aspirations.

This study addresses a gap in the literature, namely a lack of information about Al women's educational aspirations for higher education. Future research should focus on additional factors that may affect aspirations and reasons that Als do not pursue higher education. Research involving young Al women while in middle and high school, or conducting a longitudinal study of a cohort of such women, would further understanding.

The current exploratory study was a first step to obtaining insights into the schooling and non-schooling experiences of Al women and their effect on aspirations for higher education. The findings indicate that academic engagement, community and culture, resiliency to challenges, and knowledge of higher education processes can result not only in aspirations, but also in successful completion. The study provided a glimpse into the lives of Al women and their educational journeys.

\section{References}

American Human Development Project. (2009). Goals for the common good: Exploring the impact of education. Brooklyn, NY: American Human 
Development Project and the United Way. Retrieved from http://www.measureofamerica.org/file/common good forecaster full repo $\underline{\text { rt.pdf }}$

Astin, A. (1984). Student involvement: A developmental theory for higher education. Journal of College Student Personnel, 25, 297-308.

Astin, A. (1993). What matters in college: Four critical years. San Francisco, CA: Jossey-Bass.

Attinasi, L. S. (1992) Rethinking the study of the outcomes of college attendance. Journal of College Student Development, 33, 61-70.

Aud, S., Hussar, W., Kena, G., Bianco, K., Frohlich, L., Kemp, J., \& Tahan, K. (2011). The condition of education 2011 (NCES 2011-033). U.S. Department of Education, National Center for Education Statistics. Washington, DC: U.S. Government Printing Office. Retrieved from http://nces.ed.gov/pubsearch/pubsinfo. asp?pubid=2011033

Barnhardt, R., \& Kawagley, A. O. (2008). Indigenous knowledge systems and Alaska Native ways of knowing. Anthropology and Education Quarterly, 36(1), 8-23.

Brayboy, B. M. J. (2004). Hiding in the ivy: American Indian students and visibility in elite educational settings. Harvard Educational Review, 71(2), 125-152.

Brayboy, B. M. J. (2005a). Toward a tribal critical race theory in education. The Urban Review, 37(5), 425-446.

Brayboy, B. M. J. (2005b). Transformational resistance and social justice: American Indians in Ivy League universities. Anthropology and Education Quarterly, 36(3), 193-211.

Brickman, S. J., \& Miller, R. B. (2001). The impact of sociocultural knowledge on future goals and self-regulation. In D. M. Mclnerney \& S. Van Etten (Eds.), Research on sociocultural influences on motivation and learning (pp. 119137). Greenwich, CT: Information Age Publishing.

Brickman, S., McInerney, D. M., \& Martin, A. (2009). Examining the valuing of schooling as a motivational indicator of American Indian students: Perspectives based on a model of future oriented motivation and selfregulation. Journal of American Indian Education, 48(2), 33-54.

Carnevale, A. P., Smith, N., \& Strohl, J. (2010, June). Help wanted: Projections of jobs and education requirements through 2018. Washington, DC: The Georgetown University Center on Education and the Workforce. Retrieved from http://cew.georgetown.edu/jobs2018/

Castagno, A. E. (2005). Extending the bounds of race and racism: Indigenous women and the persistence of the Black-White paradigm of race. The Urban Review, 37(5), 447-468. 
College Board. (2007). Education pays: The benefits of higher education for individuals and society. Retrieved from http://www.collegeboard.com/ prod downloads/about/ news info/trends/ed pays 2007.pdf

Corwin, Z. B, Venegas, K. M., Oliverez, P. M., \& Colyar, J. E. (2004). School counsel: How appropriate guidance affects college going. Urban Education, 39(4), 442- 457.

Doyle, A., Kleinfeld, J., Reyes, M. (2009). The educational aspirations/attainment gap among rural Alaska Native students. The Rural Educator, 30(3), 2533.

Fann, A. (2004). Forgotten students: American Indian high school students' narratives on college going. Los Angeles, CA: UCLA Graduate School of Education \& Information Studies.

Glesne, C. (1999). Becoming qualitative researchers: An introduction ( $2^{\text {nd }}$ ed.). New York, NY: Addison Wesley Longman.

Guillory, R. M., \& Wolverton, M. (2008). It's about family: Native American student persistence in higher education. The Journal of Higher Education, 79(1), 58-87.

HeavyRunner, I., \& DeCelles, R. (2002). Family education model: Meeting the student retention challenge. Journal of American Indian Education, 41(2), 29-37.

Jaime, A. M. (2003). A room without a view from within the ivory tower. American Indian Quarterly, 27(1\&2), 254-263.

Kanu, Y. (2006). Getting them through the pipeline: Critical elements of instruction influencing school success among Native Canadian high school students. Journal of Advanced Academics, 18(1), 116-145.

Kvale, S. (1996). Interviewing: An introduction to qualitative research interviewing. Thousand Oaks, CA: Sage.

Lee, T. S. (2007). Successes and challenges in higher education transitions. Tribal College Journal, 19(1), 30-35.

Lincoln, Y. S., \& Guba, E. G. (1985). Naturalistic inquiry. Beverly Hills, CA: Sage.

Lumina Foundation for Education. (2010 September). A stronger nation through higher education. Retrieved from http://www.luminafoundation.org/states landing/a stronger nation through education/

Moll, L. C., Amanti, C., Neff, D., \& Gonzales, N. (2001). Funds of knowledge: Using a qualitative approach to connect homes and classrooms. Theory Into Practice, 31(2), 132-141.

Miller, R. B., \& Brickman, S. J. (2004). A model of future-oriented motivation and self- regulation. Educational Psychology Review, 16(1), 9-35.

Linares-Rendón, L. I., \& Muñoz, S. M. (2011). Revisiting validation theory: Theoretical foundations, applications, and extensions. Enrollment 
Management Journal, 5(2), 12-33. Retrieved from http://www.tgslc.org/pdf/ emj-s11.pdf

National Center for Education Statistics. (2010). Status and trends in the education of racial and ethnic minorities. Washington, DC: U.S. Department of Education. Retrieved from http://nces.ed.gov/pubs2010/ 2010015/intro.asp

National Center for Education Statistics. (2012). The condition of education. Washington, D.C: U.S. Department of Education. Retrieved from http://nces.ed.gov/pubsearch/pubsinfo.asp?pubid=2012045

Rendón, L. I. (1994). Validating culturally diverse students: Toward a new model of learning and student development. Innovative Higher Education, 19(1), 33-51.

Saggio, J. J., \& Rendón, L. I. (2004). Persistence among American Indians and Alaska Natives at a Bible college: The importance of family, spirituality, and validation. Christian Higher Education, 3, 223-240.

Shotton, H. J., Oosahwe, S. L., \& Cintrón, R. (2007). Stories of success: Experiences of American Indian students in a peer-mentoring retention program. The Review of Higher Education, 31(1), 81-107.

Tesch, R. (1990). Qualitative research: Analysis types and software tools. New York, NY: Falmer.

Tierney, W. G., Colyar, J. E., \& Corwin, Z. B. (Eds.) (2005). Preparing for college: Nine elements of effective outreach. Albany, NY: State University of New York.

Tierney, W. G., \& Venegas, K. M. (2006). Fictive kin and social capital: The role of peer groups in applying and paying for college. American Behavioral Scientist, 49(12),1687-1702.

Tierney, W. G., Sallee, M. W., \& Venegas, K. M. (2007). Access and financial aid: How American-Indian students pay for college. Journal of College Admission, 197, 14-23.

Tinto, V. (1987, 1993). Leaving college: Rethinking the causes and cures of student attrition. Chicago, IL: University of Chicago Press.

Waterman, S. J. (2007). A complex path to Haudenosaunee degree completion. Journal of American Indian Education, 46(2), 20-40.

Woodcock, D. B., \& Alawiye, O. (2001). The antecedents of failure and emerging hope: American Indians and public higher education, Education, 121(4), 810-820.

Zarate, E., \& Pachon, H. P, Jr. (2006). Perceptions of college financial aid among California Latino youth. Tomas Rivera Policy Institute, Policy Brief, June 2006. Los Angeles, CA: University of Southern California. 